\title{
А.Л. Синица
}

\section{ПРОБЛЕМЫ И ПЕРСПЕКТИВЫ РАЗВИТИЯ СИСТЕМЫ ДОШКОЛЬНЫХ ОБРАЗОВАТЕЛЬНЫХ ОРГАНИЗАЦИЙ В РОССИЙСКОЙ ФЕДЕРАЦИИ ${ }^{1}$}

\begin{abstract}
В статье рассматриваются система дошкольных образовательных организаций $u$ динамика изменения числа детей дошкольного возраста в России после 1990 г. На основе прогноза населения до 2030 г. Росстата и до 2050 г. Лаборатории экономики народонаселения и демографии экономического факультета МГУ им. М.В. Ломоносова автор оценивает число детей дошкольного возраста на 01.01.2031 и 01.01.2051 г2. при разных вариантах прогноза и потребность в местах в дошкольных образовательных организачиях при разном числе детей дошкольного возраста и разном охвате детей дошкольным образованием. В заключении приводятся рекомендации для государственной политики, которые помогут компенсировать колебания спроса на места 8 дошкольных образовательных организациях при разных прогнозных оченках числа детей дошкольного возраста.

Ключевые слова: прогноз, система дошкольных образовательных организачий, число детей дошкольного возраста, охват детей дошкольным образованием, демографическое развитие, сочиальное развитие, рабочая сила, сочиальная политика.
\end{abstract}

\section{Введение}

Еще Ф. Энгельс отмечал, что женщина, «если она хочет участвовать в общественном труде и иметь самостоятельный заработок, то она не в состоянии выполнить свои семейные обязанности» [1. С. 76]. В настоящее время проблема совмещения профессиональных обязанностей с семейными является еще более актуальной, поскольку на нее накладываются постарение населения, низкая рождаемость и колебания численности населения, вызванные демографической волной.

В XX в. с его потрясениями стало окончательно ясно, что от решения этого вопроса зависит успешное социально-экономическое развитие экономически развитого государства, поэтому большинство крупных исследователей, начиная с А. Маршалла и Т. Веблена, в той или иной степени затронули в своих работах соответствующую проблематику. Практическая государственная политика, выраженная, например, в развитии сети дошкольных образовательных организаций (далее - ДОО) и создании системы родительских отпусков, подтвердила теоретические предположения. В XXI в. эта проблема станет еще более актуальной, так как демографическое развитие все сильнее влияет на экономическое (наиболее яркий пример - Китай).

\footnotetext{
${ }^{1}$ Статья подготовлена при финансовой поддержке РФФИ. Грант «Социальные и экономические последствия возможных сценариев демографического развития России (на федеральном и региональном уровнях)» № 15-06-04731.
} 
Россия не является исключением. Более того, особенности предшествующего развития свидетельствуют о том, что без гармонизации семьи и работы социальный прогресс будет гораздо ниже потенциального, что приведет к значительной социальной напряженности. С нашей точки зрения, наиболее значимыми негативными последствиями для России можно считать более низкий уровень жизни населения, числа занятых и уровня человеческого капитала, а также более низкую рождаемость.

Это ставит ряд вопросов:

- какие аспекты общественных отношений являются наиболее важными для изменений;

- какие результаты необходимы;

- какие меры позволят с наименьшими затратами достичь необходимого результата;

- что является объектом и субъектом изменений?

Аспектов общественных отношений, связанных с совмещением профессиональных обязанностей с семейными, много. К ним относятся создание дружественных к родителям рабочих мест, системы отпусков по уходу за детьми, системы льгот и пособий, а также создание и развитие «детской» инфраструктуры. К ней относятся постоянные и временные объекты и институты, которые помогают в уходе за детьми и их воспитании. В данной статье мы затронем систему ДОО, как одного из важнейших элементов государственной политики, направленной на создание условий для совмещения родителями профессиональных и семейных обязанностей.

Результаты политики зависят от целей государства. В данном случае в условиях сокращения трудоспособного населения, низкого уровня жизни населения и низкой рождаемости государству необходимо увеличивать число занятых и повышать рождаемость. Одним из способов этого является развитие сети ДОО и увеличение охвата детей дошкольных образованием.

Вопрос мер особенно важен, так как государственная политика - дорогостоящее мероприятие и цена неправильного решения высока. Стоимость создания одного места в системе ДОО в объекте капитального строительства составляет около 1 млн руб., но в условиях снижения численности населения в трудоспособном возрасте эти расходы необходимы для экономического развития страны. Тем не менее другие меры (в том числе нормативного и информационного характера) тоже нужны.

Субъектами общественных отношений являются государство, различные общественные институты, семья, отдельные люди. Объектом в данном случае является механизм создания среды, которая позволяет сочетать профессиональные обязанности с семейными на примере развития сети ДОО.

Решение рассматриваемой проблемы невозможно без учета демографических тенденций и разработки прогнозов развития на длительный период. События в сфере дошкольного образования, наблюдаемые последние 10-15 лет, продемонстрировали это в полном объеме. И все-таки в настоящее время прогнозу развития системы ДОО с учетом разной численности детей дошкольного возраста (далее - дети) уделяется на всех уровнях власти слишком мало внимания. 
В данной работе мы попытаемся сделать оценку потребности в местах в ДОО в России в целом, основываясь на прогнозе численности населения России до 2050 г., подготовленном Лабораторией экономики народонаселения и демографии экономического факультета МГУ им. М.В. Ломоносова (далее Лаборатория), и на прогнозе численности населения до 2030 г., подготовленном Росстатом. Сначала мы рассмотрим изменение некоторых характеристик системы ДОО в России за период с момента распада СССР, затем - динамику изменения числа детей дошкольного возраста в 1990-2016, 2017-2030 и 2017-2050 гг. при разных допущениях. Наконец, мы попробуем оценить число мест в ДОО, которые будут необходимы к 2030 и 2050 гг. при разной численности детей дошкольного возраста и разном охвате детей дошкольным образованием.

\section{Развитие системы ДОО до 2015 2.}

Комплексному и подробному изучению развития сети ДОО в России посвящено немного работ [2-4], поэтому рассмотрим систему ДОО в целом по стране в 1990-2014 гг., поскольку более свежие данные Росстат не публиковал. В таблице представлены некоторые характеристики развития системы ДОО за этот период. 1990-е гг. даны в меньшем объеме, так как в это время число ДОО сокращалось, но число детей сокращалось еще быстрее. В результате охват детей дошкольным образованием и очередь на получение места в ДОО снизились.

Характеристики системы ДОО в 1990-2014 гг.

\begin{tabular}{c|c|c|c|c}
\hline Год & Число ДОО & $\begin{array}{c}\text { Охват детей дошко- } \\
\text { льным образованием }\end{array}$ & $\begin{array}{c}\text { Число детей, стоящих на } \\
\text { учете для определения в } \\
\text { ДОО, тыс. чел. }\end{array}$ & $\begin{array}{c}\text { Число } \\
\text { мест ДОО } \\
\text { в ДОО }\end{array}$ \\
\hline 1990 & 87944 & & 994,8 & н.Д. \\
\hline 1995 & 68593 & & 295,3 & н.Д. \\
\hline 2000 & 51329 & 55,0 & 238,2 & н.Д. \\
\hline 2001 & 49981 & & 302,7 & н.Д. \\
\hline 2002 & 48878 & 58,1 & 404,9 & н.Д. \\
\hline 2003 & 47835 & 57,6 & 597,0 & н.Д. \\
\hline 2004 & 47185 & 57,7 & 805,0 & н.Д. \\
\hline 2005 & 46518 & 56,7 & 966,4 & 4765453 \\
\hline 2006 & 46168 & 57,6 & 1237,9 & 4763662 \\
\hline 2007 & 45730 & 58,9 & 1505,3 & 4686049 \\
\hline 2008 & 45607 & 59,3 & 1895,0 & 4863484 \\
\hline 2009 & 45346 & 58,7 & 2144,8 & 4938275 \\
\hline 2010 & 45111 & 59,2 & 2247,9 & 5031352 \\
\hline 2011 & 44884 & 60,6 & 2403,9 & 5322795 \\
\hline 2012 & 44326 & 62,1 & 2717,6 & 5708927 \\
\hline 2013 & 43187 & 63,0 & 2849,9 & 6046093 \\
\hline 2014 & 50979 & 64,6 & 2849,9 & н.Д. \\
\hline
\end{tabular}

Из таблицы видим, что число ДОО с 1990 г. постоянно снижается. Особенно сильным сокращение было в 1990-е гг., что связано с социальноэкономическими условиями тех лет. В 2000-е гг. процесс замедлился, но со- 
кращение продолжалось. Рост в 2014 г. (до 51 тыс. ДОО) связан с увеличением числа организаций, которые могут осуществлять дошкольное образование, а не с ростом числа детских садов, так как их число в 2015 г. составляло около 41,3 тыс. [5. С. 5]. Подобное решение позволило несколько снизить остроту проблемы, но не решить ее, так как детские сады - особый вид ДОО, предназначенный именно для ухода за детьми и их воспитания, а также помощи работающим родителям, его сложно заменить другими организациями системы образования. В целом по стране сокращение составило 50,9\%.

Аргументом в пользу того, что для решения проблемы необходимо увеличивать число детских садов, является продолжающееся увеличение числа детей, стоящих на учете для определения в ДОО. В условиях снижения числа самих ДОО этот показатель имеет прямую связь с рождаемостью. С 2005 г. число детей, которые находятся в очереди для получения места в ДОО, в среднем по стране возросло почти в 3 раза (на 194,9\%). Это является следствием увеличения рождаемости и ажиотажного спроса на места в ДОО, вызванного комплексом причин.

Стоит отметить, что столь значительно число детей, которым необходимо место в ДОО, увеличилось на фоне роста числа мест в системе ДОО. Это еще раз подтверждает тезис о том, что только строительство полноценных ДОО может решить проблему. С 2005 по 2013 г. число мест в ДОО в целом по стране увеличилось на 26,9\% (с 4765 тыс. до 6046 тыс.).

Наконец, последним необходимым показателем развития системы ДОО является охват детей дошкольным образованием. Это интегральный показатель, который отражает баланс между числом мест в ДОО и числом детей соответствующего возраста, но он не показывает перегруженность системы ДОО детьми и прочие проблемы, связанные с числом ДОО. Кроме того, в нем не учитываются дети в возрасте до года, хотя находиться в очереди для получения места в ДОО в этом возрасте они уже могут. Тем не менее его использование оправданно. С 2005 по 2014 г. охват детей в среднем по стране вырос с 56,7 до 64,6\%, что примерно соответствует уровню 1990 г.

Рост очереди на получение места в ДОО при увеличении числа мест в системе ДОО и охвата детей дошкольным образованием говорит о том, что потенциально возможный охват детей дошкольным образованием выше.

Мы видим, что по всем показателям до уровня 1990 г. далеко, поскольку системе ДОО долгое время не уделялось внимание в должном объеме.

\section{Динамика изменения числа детей до 2017 2. и прогноз его изменения до 2051 2.}

Работ, посвященных изменению числа детей в отдельных регионах, немного [6-8], еще меньше работ, посвященных изменению числа детей в России в целом [9] или отдельных групп детей [10]. Мы можем выделить только одну работу, в которой рассматриваются ретроспективная и перспективная численности детей дошкольного возраста [17]. При этом существует много работ, посвященных уходу за детьми и его связи с экономическим аспектами развития общества [11-16] (эта проблематика является самой разработанной), но численность самих детей интересует исследователей гораздо меньше. 
Следовательно, перед составлением прогноза мы должны рассмотреть динамику изменения числа детей за предшествующие годы. Под детьми дошкольного возраста мы подразумеваем детей в возрасте до 6,5 лет, так как далеко не все родители хотят отдавать ребенка в школу с шести лет, а согласно п. 1 ст. 67 Федерального закона от 29.12.2012 г. № 273-Ф3 «Об образовании в Российской Федерации» получение начального общего образования начинается с возраста 6,5 лет. При этом мы предполагаем, что рождаемость распределена равномерно за год. На рис. 1 представлено изменение числа детей дошкольного возраста на 01.01.1990-01.01.2016 гг.

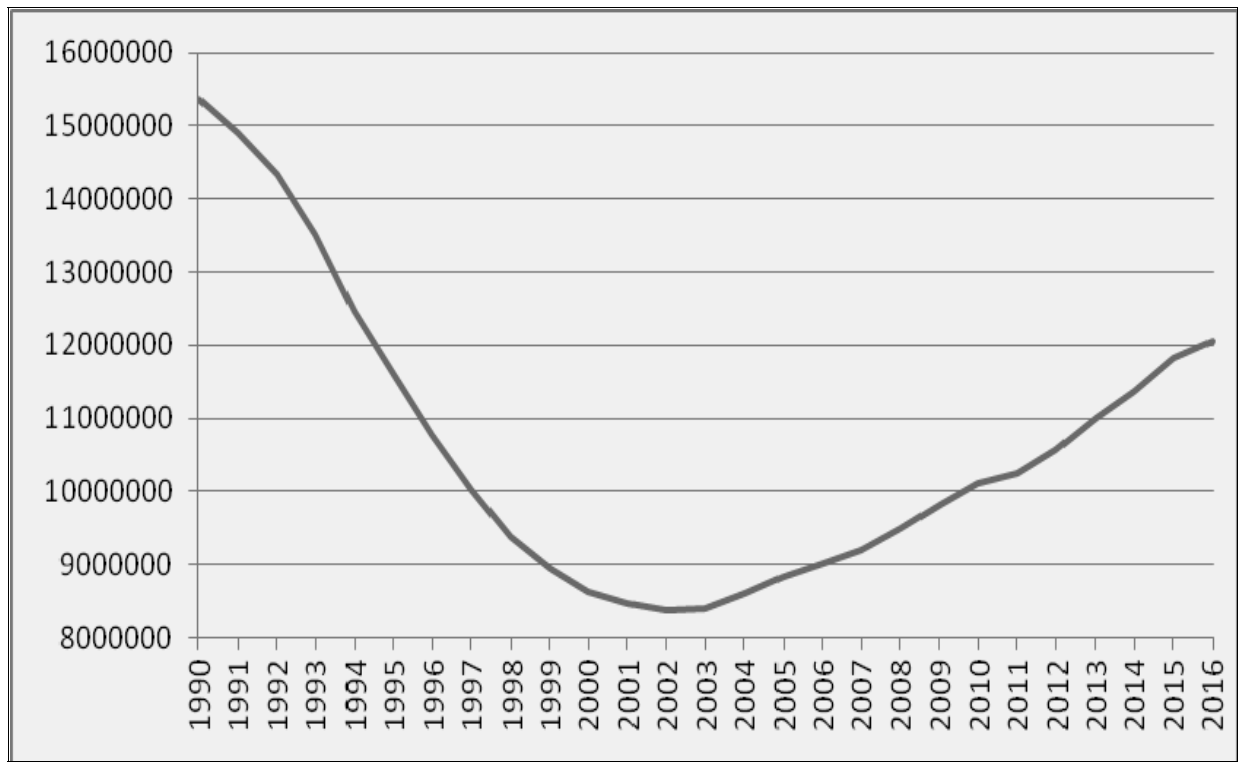

Рис. 1. Число детей дошкольного возраста в 1990-2016 гг.

На 01.01.1990 г. число детей было самым большим - 15370 тыс. чел. Это связано с демографической волной, которая была усилена мерами демографической политики 1980-х гг. Смена социального строя и социальноэкономическая нестабильность привели к снижению рождаемости в 1990-е гг. Минимальный уровень рождаемости был зафиксирован в 1999 г., но минимальное число детей (8 379 тыс. чел.) - только на 01.01.2002 г., что связано с временным лагом. С 2002 г. число детей увеличивается. На 01.01.2016 г. в стране было 12062 тыс. детей.

На рис. 2 представлен прогноз числа детей дошкольного возраста. Для его составления были использованы как данные Росстата, так и данные наших коллег, полученные в ходе работы над проектом РФФИ. Мы не будем вникать в различия относительно исходных прогнозных гипотез, поскольку не знаем предположения Росстата в полном объеме. Особенно это касается смертности и миграции. Выделим лишь наиболее важные положения. Вопервых, в прогнозе Лаборатории прогнозные гипотезы носят более пессимистический характер по сравнению с гипотезами Росстата, и это хорошо видно 
на рисунке. Во-вторых, в прогнозе Росстата выделены только три прогнозных варианта, тогда как в прогнозе Лаборатории оценка проведена для пяти вариантов. В-третьих, прогноз Росстата подготовлен до 01.01.2031 г., а прогноз Лаборатории - до 01.01.2051 г. Безусловно, множество событий внесет в прогнозы коррективы, но без прогнозов нельзя планировать социальноэкономическое развитие страны.

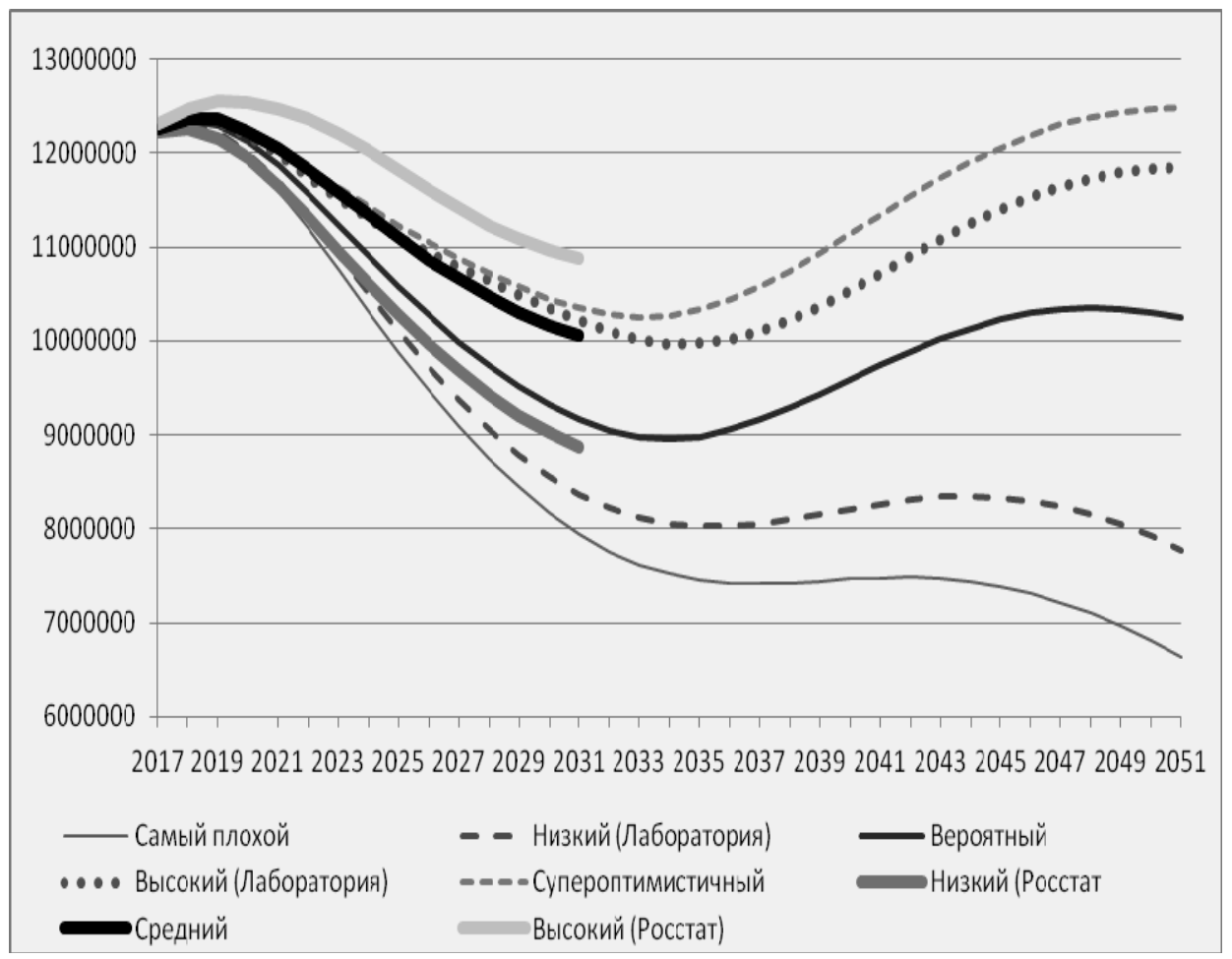

Рис. 2. Число детей дошкольного возраста в РФ до 2051 г. при различных прогнозных гипотезах

На начало 2017 г. по обоим прогнозам число детей составляет примерно 12,2-12,3 млн чел. В 2017-2018 гг. отмечается максимальная численность детей, после чего начинается ее снижение. В прогнозе Лаборатории это начнется в 2018 г., в прогнозе Росстата в 2018-2019 гг.

По всем прогнозам Росстата число детей до 2031 г. убывает. Различается лишь скорость убыли. В низком варианте прогноза число детей сокращается на 27,4\% - с 12256 тыс. чел. на 01.01.2018 г. до 8872 тыс. чел. в 2031 г. Согласно среднему варианту число детей сократится с 12363 тыс. чел. на 01.01.2018 г. до 10059 тыс. чел. (на 18,0\%). Высокий вариант прогноза предусматривает сокращение числа детей с 12553 тыс. чел. на 01.01.2019 г. до 10871 тыс. чел. (на 11,7\%). Мы видим, что ближе к 2031 г. снижение числа детей замедляется, и можем предполагать его увеличение с середины 2030-х гг. 
Прогноз Лаборатории составлен для более длинного временного отрезка, поэтому динамика изменения числа детей более сложная и позволяет увидеть волнообразную структуру населения России.

При самом плохом развитии событий на 01.01.2018 г. прогнозируется 12300 тыс. детей. Начавшееся затем снижение продлится до 2036 г. и число детей сократится до 7428 тыс. чел. (на 01.01.2037 г.). До 01.01.2043 г. оно слабо увеличится, достигнув 7482 тыс. чел., после чего вновь начнется снижение. На 01.01.2051 г. прогнозируется 6634 тыс. детей.

Низкий вариант прогноза предполагает 12323 тыс. детей на 01.01 .2018 г. Число детей согласно этому варианту будет сокращаться по 01.01.2035 г., когда в стране будет всего 8025 тыс. детей. До 01.01.2044 г. прогнозируется скромный рост (до 8349 тыс. чел.). Последующий спад сократит число детей на 01.01.2051 г. до 7777 тыс. чел.

Согласно вероятному прогнозу на 01.01.2018 г. в стране будет 12347 тыс. детей. На 01.01.2034 г. прогнозируется 8954 тыс. детей. С 01.01.2035 г. начнется рост, который продлится до 01.01.2048 г. (10350 тыс. детей). На 01.01.2051 г. в стране будет 10243 тыс. детей.

Высокий вариант прогноза предусматривает на 01.01.2018 г. 12369 тыс. детей. Последующий спад длится до 01.01.2034 г. (минимум составляет 9968 тыс. детей). С 01.01.2035 г. начинается рост. На 01.01.2051 г. прогнозируется 11855 тыс. детей, что всего на 400 тыс. чел. меньше максимального уровня 2018 г. В данном варианте прогноза рост числа детей замедляется к 2051 г., но все еще продолжается.

При самом благоприятном развитии событий на 01.01.2018 г. достигается локальный максимум числа детей (12374 тыс. человек). Он снижается до 2032 г. (на 01.01.2033 г. по прогнозу предполагается 10250 тыс. детей). На 01.01.2051 г. достигается абсолютный максимум числа детей - 12481 тыс. чел. Это единственный вариант прогноза, в котором по состоянию на 2051 г. число детей выше, чем в 2017-2019 гг. При этом увеличение числа детей продолжается и мы можем предполагать достижение уровня в 12500 тыс. детей.

Мы видим, что число детей изменяется волнообразно: за снижением, которое начнется в 2018-2019 гг. и продлится до середины 2030-х гг., последует рост, который затем вновь сменится снижением числа детей (за исключением высокого и супероптимистичного вариантов прогноза Лаборатории). Это связано с изменением численности населения в репродуктивном возрасте. Первый спад обусловлен снижением рождаемости в 1980-е гг. после относительно высокой рождаемости 1990-х гг., вызванной как мерами демографической политики, так и демографической волной, сформированной во время войны и после нее. Последующий рост связан с повышением рождаемости в 2000-2010-х гг., но число рожденных в это время детей меньше, поэтому можно предполагать, что их рождаемость не позволит достичь числа детей, рожденных в 1980-е гг. Увеличение возможно только, если ожидаемое и желаемое числа детей возрастут, т.е. будет наблюдаться увеличение потребности в детях. Второй спад связан с малочисленным поколением 2020-х гг., которое также может достичь минимума рождаемости на очень низком уровне. 


\section{Прогноз потребности числа мест в ДОО до 2050 2.}

Для прогноза потребности в числе мест в ДОО необходимо сделать предположение в отношении требуемого охвата детей дошкольным образованием.

Очевидно, что в условиях снижения численности рабочей силы из-за вступления в трудоспособный возраст малочисленных поколений и наличия значительного спроса на услуги ДОО охват детей системой ДОО должен увеличиваться. Мы считаем, что охват должен увеличиться до уровня не менее 75\%. Выбор такого порогового значения связан с двумя причинами. Во-первых, в условиях снижения числа детей система ДОО сможет достигнуть этого значения при меньшем объеме затрат. Во-вторых, существуют родители, которые предпочли бы сами воспитывать детей, а не отдавать их в ДОО. Доля таких родителей достаточно велика - 10-15\% [18. С. 65], хотя для ее уточнения нужны более современные данные. О том, что на ДОО спрос предъявляют 75\% родителей, говорят и другие исследователи [17. С. 52].

Следует сказать несколько слов и о неоднородности охвата детей дошкольным образованием на уровне федеральных округов. В регионах Южного, Северо-Кавказского и Сибирского федеральных округов с преимущественно сельскохозяйственной ориентацией и культурными особенностями, связанными с ценностью семьи и семейной жизни, охват детей сетью ДОО ниже среднего по стране, а в регионах Севера - выше среднего, что связано с климатическими условиями и особенностями освоения этих территорий.

Учитывая неоднородность охвата и потребность в местах в ДОО по стране, мы решили остановиться на уровне $75 \%$, хотя расчеты сделаны и для уровней 70 и $80 \%$.

Потребность в местах мы рассчитываем как охват детей в возрасте 16,5 года, хотя детей в возрасте до двух лет в системе ДОО мало. Безусловно, удовлетворенность населения уровнем развития сети ДОО достигается не при каком-то уровне охвата (50, 80, 100\% или ином), а при условии, когда все родители могут отдать своего ребенка в ДОО в том возрасте, в котором они считают нужным, и получить место в нем. Тем не менее количественное выражение этой ситуации необходимо, поэтому мы ввели представленный выше критерий.

На рис. 3 дана динамика изменения потребности в местах в ДОО при разном требуемом уровне охвата детей и разной численности детей. По состоянию на 2013 г. в системе ДОО было чуть более 6 млн мест. К сожалению, мы лишь можем предполагать, что их число увеличилось, но на сколько - неизвестно. В связи с этим в качестве граничного значения остался уровень 2013 г. 


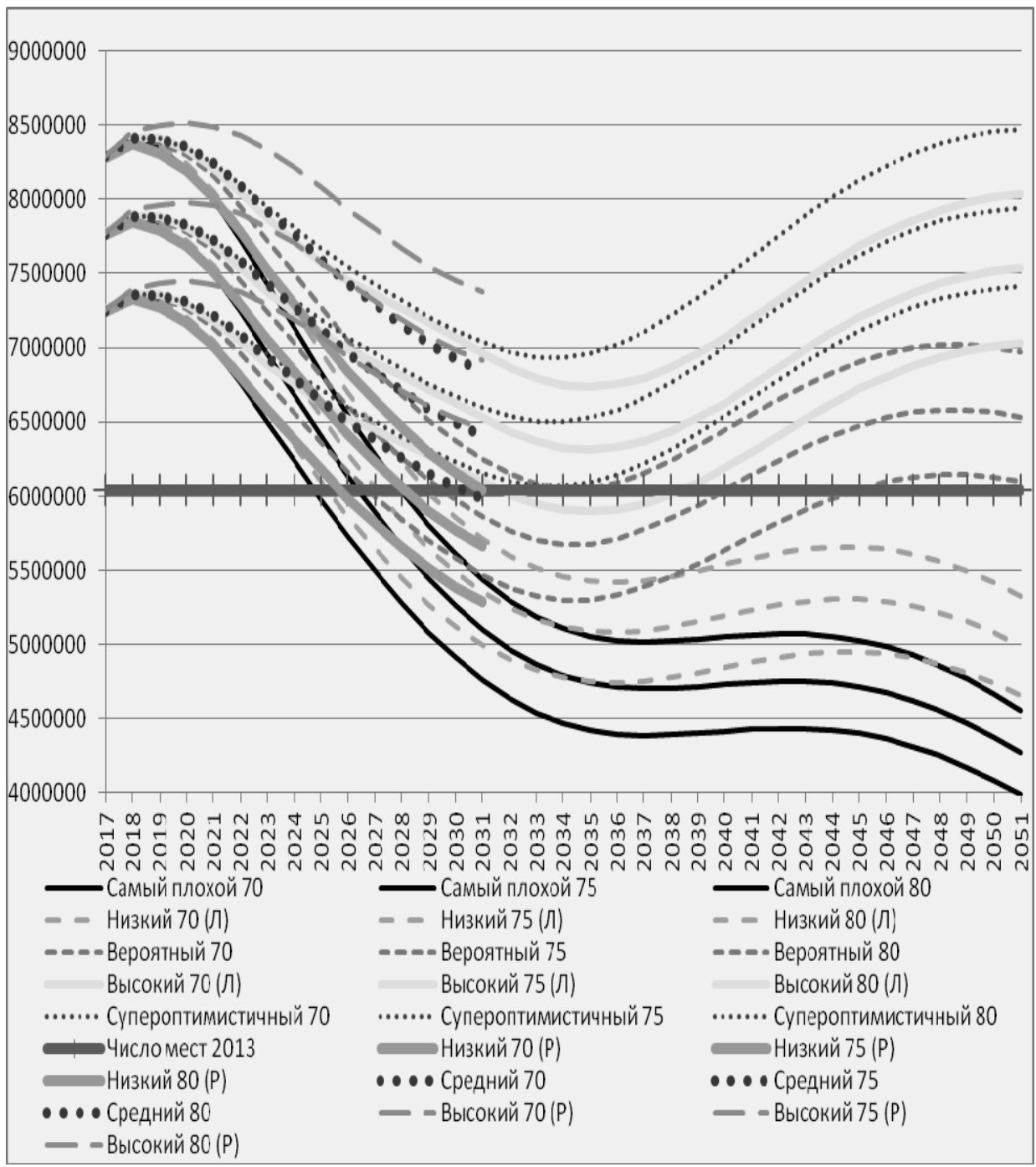

Рис. 3. Потребность в местах в ДОО до 2051 г.

Начнем с прогноза Лаборатории. Согласно самому пессимистическому развитию событий в 2026-2029 гг. число детей снизится настолько, что существующих мест будет не только достаточно, но и слишком много и потребуется их снижение. Такая же картина наблюдается и в отношении низкого прогноза числа детей, но в нем число детей снизится в 2026-2030 гг. В этих прогнозах число детей снижается сильно и 6 млн мест явно являются избыточными. Оба этих варианта не соответствуют целям демографического развития России, поскольку предполагают крайне низкий уровень рождаемости и являются нежелательными. При изменении числа детей по вероятному варианту число мест соответствует требуемому охвату детей с 2027-2033 по 2036-2044 гг. В случае реализации вероятного сценария роль различных 
вспомогательных институтов и трансформируемых мест в ДОО будет очень велика. В соответствии с высоким прогнозом демографического развития существующих в ДОО мест достаточно только при охвате на уровне $70 \%$ в 2033-2037 гг. Для остальных лет и при прочих вариантах для достижения нужного охвата детей необходим ввод дополнительных мест. При самом оптимистичном варианте развития событий существующих мест тем более недостаточно. Более того, при реализации двух последних вариантов необходим ввод большого числа постоянных мест, чего можно достигнуть только при вводе в систему ДОО новых организаций.

Рассмотрим потребность в местах в ДОО согласно прогнозу Росстата. По низкому прогнозу текущее число мест станет достаточным к 2026-2031 гг. При среднем прогнозе существующее число мест позволит достигнуть охвата $70 \%$ лишь к 2030 г., а для достижения более высокого уровня охвата требуется ввод дополнительного числа мест. При реализации высокого варианта очевидно, что существующего числа мест недостаточно для обеспечения требуемого охвата ни при каком варианте.

Мы видим, что со стороны органов власти возможно три модели поведения. Во-первых, можно продолжать снижать число ДОО. Такое решение проблемы допустимо только при низких вариантах прогноза, которые предполагают существенное сокращение числа детей по сравнению с текущим уровнем. Во-вторых, органы власти могут зафиксировать текущее число ДОО, а нехватку мест решать путем создания мест в ДОО (уплотнение групп) и школах (например, в виде образовательных комбинатов), развития частных ДОО и института сертифицированных нянь. Такое решение возможно при средних вариантах прогноза, но оно не всегда допустимо, поскольку уплотнение групп ведет к более низкому уровню человеческого капитала у детей, частные ДОО слишком дороги для большей части населения, а профессиональные качества нянь не всегда возможно проконтролировать. В связи с этим создание новых ДОО тоже является мерой, которая позволяет адекватно реагировать на изменение числа детей при среднем варианте прогноза. Третьим решением служит увеличение числа ДОО. Этот вариант обязателен при реализации высоких вариантов прогнозов, так как прочие меры являются лишь субститутами, которые не позволяют решить проблему сразу, а отодвинут ее решение в будущее, т.е. не подходят для решения долгосрочных задач. При этом для решения частных задач они могут дополняться мерами, предложенными для среднего варианта развития событий.

Прогнозы показывают большую вариативность потребности в местах в ДОО. Даже через пять лет варианты различаются уже на 1 млн мест, что является значительной величиной. В связи с этим для органов власти становится очень важным предусмотреть демографические тенденции и внести коррективы в программы социально-экономического развития. Мы надеемся, что подобные работы для федерального и регионального уровней помогут им принять решения, которые лучше учитывают потребности населения.

К какому году государство сможет обеспечить охват детей дошкольным образованием на уровне 70,75 и $80 \%$ при разной численности детей в возрасте $1-6,5$ года? 
Однозначно ответить на этот вопрос нельзя, поскольку ответ на него зависит от целей государства, его финансовых возможностей, динамики изменения числа детей, культурных особенностей и других обстоятельств. Тем не менее мы предполагаем, что охват даже на уровне $70 \%$ вряд ли будет достигнут в ближайшие пять лет, поскольку очередь для получения места в ДОО слишком велика. При планировании на более длительную перспективу такие факторы, как цели государства и его финансовые возможности, начинают играть слишком большую роль, чтобы их можно было корректно спрогнозировать. Ранее мы отметили, что в условиях снижения численности рабочей силы для вовлечения родителей в трудовые отношения необходимо повышать охват детей дошкольным образованием. Однако какие цели и задачи ставит перед собой государство, мы не знаем, и это является не нашим делом, а делом органов власти. Мы можем лишь показать потребность в местах в ДОО при разных вариантах развития событий (что было сделано) и дать рекомендации для разработки государственной политики в отношении данного вопроса (что будет сделано в заключении), а также объяснить последствия того или иного решения.

\section{Выводы и рекомендации}

Какие выводы мы можем сделать?

Во-первых, число детей изменяется волнообразно. Это связано с демографической волной, сформированной в 1940-1950-е гг. и усиленной событиями 1980-1990-х гг.. В связи с этим органам власти следует уделить особое внимание мерам, направленным на сглаживание демографических волн и выравнивание возрастной структуры населения. Такие меры помогут лучше планировать бюджет и сделать его менее зависимым от возрастной структуры населения, а следовательно, более одинаковым для разных лет.

Во-вторых, в настоящее время уровень развития сети ДОО низкий: число организаций сокращается, очередь в них растет. Со снижением числа детей острота проблемы будет спадать и перед органами власти встанет вопрос о балансировке сети ДОО в условиях волнообразного изменения числа детей. В связи с этим меры, позволяющие варьировать число мест в системе ДОО, являются крайне актуальными и их разработка должна быть одним из важных направлений социально-экономической политики. Если смотреть более широко, то возможность перепрофилирования должна иметь вся «детская» инфраструктура [17. С. 55].

В-третьих, при разработке политики особое внимание следует уделить региональному компоненту, поскольку различия по уровню рождаемости и охвату детей дошкольным образованием между регионами достаточно велики. Наиболее это актуально для регионов Северного Кавказа и Юга России, а также регионов Севера.

В-четвертых, в условиях снижения численности населения в трудоспособном возрасте и его низкого уровня жизни необходимо повышать охват детей дошкольным образованием. Анализ возможных вариантов повышения охвата детей при различной динамике изменения числа детей показывает, что 
большой разброс результатов и достижение того или иного уровня охвата зависят от целей государства.

В-пятых, существует достаточно много мер, направленных на снижение нагрузки на систему ДОО, которые имеют разную стоимость, поэтому их выбор - достаточно сложная задача. Следовательно, роль прогноза изменения числа детей важна.

Какие меры государственной политики, ставящей своей целью гармонизацию профессиональных и семейных обязанностей и направленных на смягчение последствий демографических волн и снижение затрат государства, можно предложить?

Можно выделить несколько мер государственной политики, направленных на изменение текущего положения.

Необходимо развитие системы ДОО, поскольку в настоящее время удовлетворенность населения уровнем развития сети ДОО низкая. Она определяется такими характеристиками, как:

- наличие развитой сети ДОО, которая имеет достаточное количеств мест для всех желающих;

- эффективность размещения дошкольных учреждений (насколько равномерно детские сады различного типа размещаются в пределах региона, могут ли родители выбирать необходимый им сад или есть препятствия);

- уровень качества услуг, предоставляемых ДОО (имеют ли родители возможность выбрать то учреждение, уровень услуг которого: график работы, размер оплаты, квалификация персонала и т.п. - кажется им приемлемым);

- возрастной фактор (возможность отдать ребенка в дошкольное учреждение в возрасте, который устраивает родителей).

Очевидно, что система ДОО не удовлетворяет данным критериям.

Решением, которое часто используется, является уплотнение групп в ДОО. При увеличении размера групп в ДОО до уровня свыше 20 человек человеческий капитал таких детей в последующие периоды накапливается медленнее [19]. Это связано с тем, что у воспитателей остается меньше времени для общения с ребенком и исправления существующих недостатков. Следовательно, необходимо увеличивать число ДОО, и эта мера должна считаться основной, но обязательно учитывать и влияние демографических волн. Это можно сделать несколькими путями.

Строить ДОО необходимо с учетом возможности перепрофилирования. Например, при низкой численности детей места могут отдаваться для нужд среднего образования и возвращаться в систему ДОО при увеличении числа детей. На основе прогнозов изменения числа детей и потребности в местах следует выделять в системе ДОО постоянный и изменяемый фонды [20-21]. Постоянный фонд является основным. К нему относятся объекты капитального строительства как не предполагающие каких-либо изменений, так и с предусмотренной возможностью изменений. Переменный фонд является вспомогательным, и к нему относятся мобильные объекты, используемые непродолжительное время, которые могут быть легко перемещены в другой регион. 
Опыт других стран показывает, что сеть муниципальных ДОО должна дополняться иными организациями и институтами, которые носят вспомогательный характер.

Негосударственные ДОО могут иметь несколько организационноправовых форм: индивидуальный предприниматель, семейный детский сад для многодетных, частный детский сад. Государство нацелено на развитие всех трех.

Стоимость услуг частных ДОО составляет 10-20 тыс. руб. в месяц, однако для ряда родителей они необходимы и при такой стоимости. В настоящее время частные ДОО составляют 5-10\% от всех услуг дошкольного образования, хотя в некоторых регионах их доля выше [22], но государство планирует развивать их (распоряжение Правительства РФ от 30.12.2012 г. № 2620-p).

Для дополнительной поддержки семей с детьми можно ввести на муниципальном уровне институт сертифицированных нянь. Такая мера должна считаться дополнительной к уже существующим, которая призвана поддержать имеющуюся сеть ДОО (особенно в отношении детей в возрасте до трех лет из-за практически полного отсутствия института яслей). Опыт создания такого института есть в европейских странах, например в Германии (более подробно см. [23]).

Это было бы полезным родителям и муниципальным властям, поскольку положительно повлияло бы на улучшение демографической ситуации в стране и повышение уровня жизни населения. Из-за более гибкого подхода ко времени ухода родителям будет проще найти официальную работу. При этом качество ухода за ребенком будет таким же, а он сам будет воспитываться в семье, психоэмоциональный климат которой заменить нельзя. Родители, которые хотели бы воспитывать детей дома, получат официальный заработок, включенный в трудовой стаж, и соответствующие социальные отчисления. Кроме того, это может привести к увеличению доли людей, использующих неоплачиваемую часть отпуска по уходу за ребенком, и повлиять на репродуктивные установки.

Наконец, подобная мера позволит поднять престиж труда по уходу за детьми, а общество станет более осведомленным об их образе жизни. Это означает, что они будут включены в жизнь общества более полно.

Повышение значимости подобного труда должно быть направлено как на семейную, так и на внесемейную его форму, ведь в настоящее время они не взаимозаменяют, а взаимодополняют друг друга. Для достижения этого следует использовать не только материальные, но и пропагандистские меры. К ним следует отнести повышение заработной платы воспитателей ДОО, а также создание благоприятного отношения в обществе к уходу за детьми (развитие «детской» инфраструктуры, повышение престижа профессий, связанных с уходом за детьми, и поощрение более благожелательного отношения работодателей к семейной форме ухода за детьми).

Последний вывод касается необходимости более тщательного планирования социальных процессов, для чего требуется знание предшествующего течения социальных процессов, текущего положения дел и прогнозов изменения численности населения, для которого и осуществляется социальноэкономическое развитие страны. Существующую неблагоприятную ситуа- 
цию можно было предвидеть, поскольку демографическая волна сформировалась давно, но сделано этого не было, в том числе и из-за отсутствия прогнозов изменения числа детей. В результате в настоящее время из-за слабого учета последствий принимаемых решений экономика и население сталкиваются с трудностями, которых можно было избежать. Схожие проблемы можно ожидать и в середине 2030-х гг., поэтому необходимо более активно использовать прогнозы изменения числа детей и готовить для органов власти кадры, которые понимали бы их значимость для социально-экономического развития страны и могли бы более полно учесть последствия принимаемых решений.

\section{Лuтература}

1. Энгельс Ф. Происхождение семьи, частной собственности и государства. В связи с исследованиями Льюиса Г. Моргана // К. Маркс. Ф. Энгельс. Собр. соч. Т. 21. М.: Гос. изд-во полит. лит., 1961. С. 23-178.

2. Селиверстова И.В. Охват детей дошкольным образованием: уровень, межрегиональная дифференциация и ее причины // Вопросы образования. 2008. № 3. С. 199-209.

3. Синица А.Л. Труд по уходу за детьми дошкольного возраста: сочетание домашней и общественной форм. М.: ТиРу, 2012. $176 \mathrm{c}$.

4. Сухова А.С. Услуги по уходу за детьми: масштабы и факторы потребления российскими семьями // Журн. исследований социальной политики. 2011. № 4. С. 473-494.

5. Ливанов Д.В. О готовности системы образования к началу 2015-2016 учебного года. Работа правительства в цифрах и фактах // Вестн. образования. 2015. Сентябрь. № 17. С. 5-12.

6. Лапыгин Ю.Н., Крылов В.Е. Прогноз развития дошкольного образования // Вестн. Владим. гос. ун-та им. Александра Григорьевича и Николая Григорьевича Столетовых. Серия «Экономические науки». 2015. № 4. С. 118-125.

7. Казарина Л.А., Шабалина Е.И. Доступность дошкольного образования как фактор активизации ресурсного потенциала региона // Изв. Иркут. гос. экон. академии. 2015. № 2(6). URL: http://eizvestia.isea.ru/reader/article.aspx?id=20038

8. Чиликова И.А., Забержинский Б.Э. Решение проблем нехватки мест в детсадах и повышения занятости населения в Самарской области через развитие частного или государственночастного партнерства // Государство и бизнес. Современные проблемы экономики: материалы VII Междунар. науч.-практ. конф. / Северо-Западный институт управления РАНХиГС при Президенте РФ, факультет экономики и финансов. СПб.: Информационный издательский учебнонаучный центр «Стратегия будущего», 2015. С. 187-190.

9. Чуваткин П.П., Материкина А.Е. О социально-экономической роли дошкольного образования // Современная научная мысль. 2015. № 2. С. 133-144.

10. Синица А. Л. Уход за детьми дошкольного возраста и демографическая безопасность России // Национальные интересы: приоритеты и безопасность. 2016. № 12. С. 188-198.

11.Внуковская T.Н. Теория и методология рисков репродуктивного труда. М.: ООО «Издательство “Мир науки"», 2014. 252 с.

12.Илышев А.М., Багирова А.П. Введение в репродуктивистику. Становление науки о воспроизводстве человека. М.: Финансы и статистика, 2010. 304 с.

13.Ильиеев А.М., Лаврентьева И.В. Стратегия включения репродуктивного труда в экономику России. М.: Финансы и кредит, 2005. 368 с.

14.Шубат О.М., Пшеничникова М.М. Родительский труд в малых городах России: опыт экономико-статистического исследования в Уральском регионе // Региональная экономика: теория и практика. 2012. № 15. С. 20-29.

15. Синица А.Л. Затраты на уход за детьми дошкольного возраста в структуре расходов на детей: теоретический анализ // Национальные интересы: приоритеты и безопасность. 2016. № 6 (339). С. $146-157$.

16. Синииа А.Л. Труд по уходу за детьми дошкольного возраста как инструмент экономического развития России // Научные исследования экономического факультета: электрон. журн. экономического факультета МГУ им. М.В. Ломоносова. 2014. Т. 6, № 1. С. 149-169. 
17.Калабихина И.Е. Демографическая волна рождений и будущие колебания численности населения в разных возрастных группах: вызовы для социальной политики // Экономические стратегии. 2015. Т. 17, № 2. С. 50-57.

18.Ильшев А.М., Лаврентьева И.В. Стратегии включения репродуктивного труда в производство // Социологические исследования. 2003. № 3. С. 58-66.

19. Chetty R., Friedman J.N., Hilger N. et al. How does your kindergarten classroom affect your earnings? Evidence from project STAR. NBER Working Paper 16381, September 2010. URL: http://www.nber.org/papers/w16381

20.Долгов A.B., Сычева Е.Б. Методика проектирования и расчета сети дошкольных организаций в условиях демографической нестабильности // Акад. вестн. УралНИИПроект РААСН. 2013. № 4. С. 60-64.

21.Долгов А.В., Сычева Е.Б. Особенности формирования фонда дошкольных объектов в условиях демографической динамики // Акад. вестн. УралНИИПроект РААСН. 2014. № 4. С. 5355 .

22. Стариков Н.B., Ткачев A.A. Социологический анализ востребованности услуг частных детских садов // Современные проблемы науки и образования. 2012. № 6. С. 733. URL: http://www.science-education.ru/pdf/2012/6/548.pdf

23. Саралиева Э.Х., Соловьева С.В. Альтернативные формы поддержки успешной семьи: проект «дневные мамы» // Женщина в российском обществе. 2008. № 3. С. 14-23.

\section{Sinitsa A.L., Lomonosov Moscow State University (Moscow, Russia). E-mail: sinitsa@econ.msu.ru PROBLEMS AND FUTURE DEVELOPMENT OF THE PRE-SCHOOL EDUCATIONAL ORGANIZATIONS SYSTEM IN THE RUSSIAN FEDERATION}

Keywords: predictions, pre-school educational organizations system, the pre-school children number, coverage of children with preschool education, demographic development, social development, labor, social policy.

The pre-school educational organizations system and the dynamics of pre-school children number changes in Russia after 1990 are considered in the article. According to the population predictions until 2030 made by Russian Statistics Committee and ones until 2050 made by the laboratory of population economy and demography of the Moscow State University economic faculty the author estimates a preschool children number to 2031 and 2051 considering different prediction versions. Also the author evaluates the need for places in pre-school educational organizations considering different pre-school children number and different coverage of children with pre-school education. In conclusion, recommendations for public policy, which compensate demand fluctuations for places in pre-school educational organizations with different predictive estimates of the pre-school children number, are given.

\section{References}

1. Engels F. Proiskhozhdeniye semi, chastnoy sobstvennosti i gosudarstva. V svyazi s issledovaniyami Lyuisa G. Morgana // Marks K. Engels F. Collected Works T. 21. M.: State Publishing House of Political Literature, 1961. pp. 23-178.

2. Seliverstova I.V. Okhvat detey doshkolnym obrazovaniyem: uroven, mezhregionalnaya differentsiatsiya i yeye prichiny // Voprosy obrazovaniya. 2008. № 3. pp. 199-209.

3. Sinitsa A.L. Trud po ukhodu za detmi doshkolnogo vozrasta: sochetaniye domashney i obshchestvennoy form. M. M.: TiRu, 2012. pp. 176.

4. Sukhova A.S. Uslugi po ukhodu za detmi: masshtaby i faktory potrebleniya rossiyskimi semyami // Zhurnal issledovaniy sotsialnoy politiki. 2011. № 4. pp. 473-494.

5. Livanov D.V. O gotovnosti sistemy obrazovaniya k nachalu 2015-2016 uchebnogo goda. Rabota pravitelstva $v$ tsifrakh i faktakh. Vestnik obrazovaniya. 2015. Sentyabr. № 17. pp. 5-12.

6. Lapygin YU.N., Krylov V.Ye. Prognoz razvitiya doshkolnogo obrazovaniya // Bulletin of the Vladimir State University named after Alexander Grigorievich and Nikolai Grigorievich Stoletov. Series: Economic sciences. 2015. № 4. pp. 118-125.

7. Kazarina L.A., Shabalina Ye.I. Dostupnost doshkolnogo obrazovaniya kak faktor aktivizatsii resursnogo potentsiala regiona // Izvestiya Irkutsk State Economic Academy. 2015. № 2 (6). Access mode: http://eizvestia.isea.ru/reader/article.aspx?id=20038 
8. Chilikova I.A., Zaberzhinskiy B.E. Resheniye problem nekhvatki mest $\mathrm{v}$ detsadakh i povysheniya zanyatosti naseleniya $\mathrm{v}$ Samarskoy oblasti cherez razvitiye chastnogo ili gosudarstvennochastnogo partnerstva // State and business. Modern problems of the economy. Materials of the VII International Scientific and Practical Conference. North-West Institute of Management RASHiGS under the President of the Russian Federation, Faculty of Economics and Finance. SPb.: Information Publishing Education and Research Center "Strategy of the Future", 2015. pp. 187-190.

9. Chuvatkin P.P., Materikina A.Ye. O sotsialno-ekonomicheskoy roli doshkolnogo obrazovaniya // Sovremennaya nauchnaya mysl. 2015. № 2. pp. 133-144.

10. Sinitsa A.L. Ukhod za detmi doshkolnogo vozrasta i demograficheskaya bezopasnost Rossii // Natsionalnyye interesy: prioritety i bezopasnost. 2016. № 12. pp. 188-198.

11. Vnukovskaya T.N. Teoriya i metodologiya riskov reproduktivnogo truda. M.: Ltd «Publishing house "Mir nauki"», 2014. pp. 252.

12. Ilyshev A.M., Bagirova A.P. Vvedeniye v reproduktivistiku. Stanovleniye nauki o vosproizvodstve cheloveka. M.: Finansy i statistika, 2010. pp. 304.

13. Ilyshev A.M., Lavrentyeva I.V. Strategiya vklyucheniya reproduktivnogo truda v ekonomiku Rossii. M.: Finansy i kredit, 2005. pp. 368.

14. Shubat O.M., Pshenichnikova M.M. Roditelskiy trud v malykh gorodakh Rossii: opyt ekonomiko-statisticheskogo issledovaniya $\mathrm{v}$ Uralskom regione // Regionalnaya ekonomika: teoriya i praktika. 2012. № 15. pp. 20-29.

15. Sinitsa A. L. Zatraty na ukhod za detmi doshkolnogo vozrasta v strukture raskhodov na detey: teoreticheskiy analiz // Natsionalnyye interesy: prioritety i bezopasnost. 2016. № 6 (339). pp. 146-157.

16. Sinitsa A.L. Trud po ukhodu za detmi doshkolnogo vozrasta kak instrument ekonomicheskogo razvitiya Rossii // Scientific research of the economic faculty. Electronic Journal of the Faculty of Economics of Moscow State University named after Lomonosov M.V. 2014. T. 6. No. 1. pp. $149-169$.

17. Kalabikhina I.Ye. Demograficheskaya volna rozhdeniy i budushchiye kolebaniya chislennosti naseleniya $\mathrm{v}$ raznykh vozrastnykh gruppakh: vyzovy dlya sotsialnoy politiki // Ekonomicheskiye strategii. 2015. T. 17. № 2. pp. 50-57.

18. Ilyshev A.M., Lavrent'yeva I.V. Strategii vklyucheniya reproduktivnogo truda v proizvodstvo // Sociological Research. 2003. № 3. pp. 58-66.

19. Chetty R., Friedman J.N., Hilger N., et al. How does your kindergarten classroom affect your earnings? Evidence from project STAR. NBER Working Paper 16381, September 2010. Access mode: http://www.nber.org/papers/w16381

20. Dolgov A.V., Sycheva Ye.B. Metodika proyektirovaniya i rascheta seti doshkolnykh organizatsiy v usloviyakh demograficheskoy nestabilnosti // Academic Bulletin of UralNIIProyekt RAASN. 2013. № 4. pp. 60-64.

21. Dolgov A.V., Sycheva Ye.B. Osobennosti formirovaniya fonda doshkol'nykh ob"yektov v usloviyakh demograficheskoy dinamiki // Academic Bulletin of UralNIIProyekt RAASN. 2014. № 4. pp. 53-55.

22. Starikov N.V., Tkachev A.A. Sotsiologicheskiy analiz vostrebovannosti uslug chastnykh detskikh sadov // Sovremennyye problemy nauki i obrazovaniya. 2012. № 6. pp. 733. Rezhim dostupa: http://www.science-education.ru/pdf/2012/6/548.pdf

23. Saraliyeva E.Kh., Solovyeva S.V. Alternativnyye formy podderzhki uspeshnoy semi: proyekt «dnevnyye mamy» // Zhenshchina v rossiyskom obshchestve. 2008. № 3. pp. 14-23.

Sinitsa A.L. Problemy i perspektivy razvitiya sistemy doshkol'nyh obrazovatel'nyh organizacij v Rossijskoj Federacii [Problems and future development of the pre-school educational organizations system in the Russian Federation]. Vestnik Tomskogo gosudarstvennogo universiteta. Ekonomika Tomsk State University Journal of Economics, 2017, no 40, pp. 206-221. 